Wilfrid Laurier University

Scholars Commons @ Laurier

$12-18-2017$

\title{
Testing the Underlying Chemical Principles of the Biotic Ligand Model (BLM) to Marine Copper Systems: Measuring Copper Speciation Using Fluorescence Quenching
}

\author{
Tara N. Tait \\ Wilfrid Laurier University \\ James C. McGeer \\ Wilfrid Laurier University \\ Scott Smith \\ Wilfrid Laurier University, ssmith@wlu.ca
}

Follow this and additional works at: https://scholars.wlu.ca/chem_faculty

Part of the Analytical Chemistry Commons, Environmental Chemistry Commons, Environmental Health Commons, Environmental Health and Protection Commons, Oceanography Commons, Toxicology Commons, and the Water Resource Management Commons

\section{Recommended Citation}

Tait, Tara N.; McGeer, James C.; and Smith, Scott, "Testing the Underlying Chemical Principles of the Biotic Ligand Model (BLM) to Marine Copper Systems: Measuring Copper Speciation Using Fluorescence Quenching" (2017). Chemistry Faculty Publications. 12.

https://scholars.wlu.ca/chem_faculty/12

This Article is brought to you for free and open access by the Chemistry at Scholars Commons @ Laurier. It has been accepted for inclusion in Chemistry Faculty Publications by an authorized administrator of Scholars Commons@ @aurier. For more information, please contact scholarscommons@wlu.ca. 


\title{
Testing the Underlying Chemical Principles of the Biotic Ligand Model (BLM) to Marine Copper Systems: Measuring Copper Speciation Using Fluorescence Quenching
}

\author{
4 Tara, N. Tait · James C. McGeer · D. Scott Smith ${ }^{\dagger}$
}

Received: date / Accepted: date

\begin{abstract}
Speciation of copper in marine systems strongly influences the ability of copper to cause toxicity. Natural organic matter (NOM) contains many binding sites which provides a protective effect on copper toxicity. The purpose of this study was to characterize copper binding with NOM using fluorescence quenching techniques. Fluorescence quenching of NOM with copper was performed on nine sea water samples. The resulting stability constants and binding capacities were consistent with literature values of marine NOM, showing strong binding with $\log K$ values from 7.64 to 10.2 and binding capacities ranging from 15 to 3110 nmole $\mathrm{mg} \mathrm{C}^{-1}$. Free copper concentrations estimated at total dissolved copper concentrations corresponding to previously published rotifer effect concentrations, in the same nine samples, were statistically the same as the range of free copper calculated for the effect concentration in NOM-free artificial seawater. These data confirms the applicability of fluorescence spectroscopy techniques for NOM and copper speciation characterization in sea water and demonstrates that such measured speciation is consistent with the chemical principles underlying the Biotic Ligand Model (BLM) approach for bioavailability-based metals risk assessment.
\end{abstract}

Keywords Copper speciation · Fluorescence quenching - Biotic Ligand Model · Marine chemistry $\cdot$ Dissolved organic carbon $\cdot$ Natural organic matter

Trace metals, such as copper, are essential to life yet at increased concentrations toxicity can result. Anthropogenic release of copper has made it a common contaminant in marine waters (Chadwick et al., 2008). As such, there is an increased concern of the fate and bioavailability of copper in marine systems.

Tait, T. N.

Department of Chemistry and Biochemistry

Wilfrid Laurier University

E-mail: tara.n.tait@gmail.com

McGeer, J. C.

Department of Biology

Wilfrid Laurier University

E-mail:jmcgeer@wlu.ca

${ }^{\dagger}$ Corresponding Author, Smith, D.S.

Department of Chemistry and Biochemistry

Wilfrid Laurier University

E-mail: ssmith@wlu.ca 
The Biotic Ligand Model (BLM) is a predictive tool used to estimate site-specific bioavailability and toxicity of metals. The BLM is able to predict toxicity at the biotic ligand (such as the gill of a fish) based on equilibrium calculations of metal speciation using bulk water chemistry, such as $\mathrm{pH}$, salinity and dissolved organic carbon (DOC) as input parameters (Di Toro et al., 2001; Santore et al., 2001; Paquin et al., 2002). DOC is often used as a surrogate measure for NOM because DOC is easier to measure. The BLM has been adopted as a regulatory tool for freshwater copper by the U.S. EPA (2007); however, there is need for a BLM in saltwater environments. Investigations pertaining to saltwater are currently underway for application of a marine BLM; however, more information is needed before being accepted for regulatory use (Arnold, 2005). The focus of this study is to characterize marine NOM binding to copper using fluorescence spectroscopy techniques.

The speciation of copper plays a strong role on copper bioavailability and toxicity (Chadwick et al., 2008; Eriksen et al., 2001b,a; Sunda and Hanson, 1979). In particular, natural organic matter (NOM) is a heterogenous mixture of organic compounds that contain many potential binding sites for metals, such as copper. Copper can form complexes with $\mathrm{NOM}$ at binding sites such as amino $\left(\mathrm{Cu}-\mathrm{NHR},\left[\mathrm{Cu}-\mathrm{NH}_{2} \mathrm{R}\right]^{+}\right)$, carboxyl $\left(\mathrm{Cu}-\mathrm{CO}_{2} \mathrm{H}\right)$, phenolic (Cu-OAr) and sulfide or thiol groups $(\mathrm{Cu}-\mathrm{SH})$ (Smith et al., 2002). NOM can be broadly categorized into two groups, allochthonous and autochthonous. Allochthonous, or terrestrially-derived organic matter comes from the decomposition and leaching of soil and plant materials such as lignin, tannins and detritus and typically contains a higher humic and fulvic substance content. Autochthonous, or microbially-derived organic matter comes from bacterial and algal processes occurring within the water column and typically contains a higher proteinaceous content (Birdwell and Engel, 2009; McKnight et al., 2001).

Due to the wide variety of binding sites within NOM, the determination of metal binding constants is difficult. Typical stability constants for copper-NOM have been found to range from a $\log K$ of 4 to 15 (Playle et al., 1993). Natural organic matter fluoresces due to the presence of aromatic structural groups with electron-donating functional groups. This quality allows fluorescence techniques to be used to characterize NOM and metal speciation (Chen et al., 2013; da Silva et al., 1998; Smith and Kramer, 2000). The fluorescence of NOM is known to be quenched in the presence of metals such as copper, and has been used to determine conditional stability constants $(\log K)$ and binding capacities $\left(L_{T}\right)$ for fluorescent NOM (da Silva et al., 1998). Initial efforts for this characterization were performed by Ryan and Weber (1982), resulting in the well-known Ryan-Weber (RW) equation.

Here a multi-fluorophore RW method is applied to coastal seawater from a variety of sources, to determine if fluorescence quenching measured speciation is consistent with other speciation methods, including ion-selective electrodes. In addition, this current work tests if the fluorescence-estimated speciation is consistent with the assumptions of the biotic ligand model; i.e., that constant cupric ion should be observed at total dissolved copper corresponding to measured effects concentrations for a given organism. Published rotifer toxicity data ( $\mathrm{EC}_{50}$ values) for the same samples are used for these comparisons (Tait et al., 2016).

\section{Materials and Methods}

The method for storage, selection and preparation of samples is given in (Tait et al., 2016). For a brief description of sampling site locations and characteristics please refer to Table 1. These sites represent a variety of locations around the North American coast. The samples used in this study were all salinity adjusted to approximately 30 parts per thousand (Table 1) and filtered through $0.45 \mu \mathrm{m}$ filters (cellulose nitrate membrane, Whatman, Germany). 
Salting up was performed using a mixture individually purchased salts. The full details are given in Tait et al. (2016). Rotifer (Brachionus plicatilis) 24-h median effect $\mathrm{EC}_{50}$ values were determined for these same samples in a previous publication (Tait et al., 2016).

For fluorescence quenching titrations, the copper titrant solution was prepared at 157 $\mu \mathrm{M}$ from a $1000 \mathrm{mg} \mathrm{L}^{-1}$ copper standard solution (Assurance grade, SPEXCertiPrep, New Jersey, USA). The samples were $\mathrm{pH}$ adjusted to $\mathrm{pH} 8.01 \pm 0.01$ using dilute $\mathrm{NaOH}$ or $\mathrm{HCl}$, as required. Smith and Kramer (2000) determined stabilization of the fluorescence signal within 10 minutes after $\mathrm{Cu}$ addition. Thus, the solution was allowed to equilibrate for 15 minutes after each copper addition between fluorescent measurements. Three titrations were performed for each sample with three replicate fluorescent measurements per addition of titrant.

The salted-up sample was contained within a beaker with constant stirring. Aliquots were taken from the beaker and measured in a $1 \mathrm{~cm}$ quartz cuvette (Starna Cells, Inc., Atascadero, CA, USA) using a Cary Eclipse Fluorescence Spectrophotometer (Agilent Technologies Canada Inc., Mississauga, ON, CANADA). Fluorescence emission wavelengths were measured from $300 \mathrm{~nm}$ to $700 \mathrm{~nm}$ at an excitation wavelength of $270 \mathrm{~nm}$. Depending on the sample, the excitation and emission monochromator slit widths were set somewhere between 5 and $20 \mathrm{~nm}$ and the photomultiplier tube (PMT) was set to between $800 \mathrm{~V}$ and $1000 \mathrm{~V}$. The excitation and emission monochromator slit widths and PMT were varied between the given ranges in order to maximize, but not saturate, the measured fluorescence intensity. After measurement, the aliquot was returned to the beaker and the next volume of titrant was added. This process was repeated until the decrease in maximum intensity plateaued or until the total copper added to the sample was double the rotifer (Brachionus plicatilis) $\mathrm{EC}_{50}$ value reported in Tait et al. (2016) for the same sample.

All data processing was performed using MATLAB ${ }^{\mathrm{TM}}$ (MathWorks Inc., MA, USA). The fluorescent components are resolved using the total fluorescence excitation versus emission (FEEM) surface. These components were titrated against copper at fixed $\mathrm{pH}$ and salinity and then fit to a chemical equilibrium model to determine binding constants and capacities for the unknown ligands in the samples. To determine the number of fluorescent components in each sample, parallel factor analysis (PARAFAC) was performed (Tait et al., 2016) on the original samples and used to constrain the quenching data to four different fluorescent components: humic-, fulvic-, tryptophan- and tyrosine-like. A "slice" of the fluorescence surface at $270 \mathrm{~nm}$ excitation was measured for each addition of copper titrant. It is assumed that the fluorescence response is linear with concentration (Smith and Kramer, 2000) so a linear model was used for each addition of copper to estimate the contribution of each fluorophore to the measured fluorescence. The pure fluorophore components were determined via the initial PARAFAC analysis on the full FEEM. The four resolved fluophores are represented as a humic vector $(H)$, fulvic vector $(F)$, tryptophan vector $(W)$ and a tyrosine vector $(Y)$. For each emission scan obtained during titration, linear regression was used to estimate the contributions of each fluorescent species:

$$
F=k_{H} H+k_{F} F+k_{W} W+k_{Y} Y
$$

Once titration curves were generated for all of the fluorophores in a given sample the fluorescence quenching data was fit to a Ryan-Weber style model (Ryan and Weber, 1982) using multiresponse parameter estimation (Smith and Kramer, 2000). In simple terms the fluorescence for each of $p$ fluorescent components, where $p$ corresponds to the $H, F, W$ or $Y$ components, and can be represented as: 


$$
F_{p}=k_{\mathrm{L}_{p}}\left[\mathrm{~L}_{p}\right]+k_{\mathrm{ML}_{p}}\left[\mathrm{ML}_{p}\right]
$$

The fluorescence $(F)$ for each fluorophore is modelled as a linear combination of complexed (ML) and uncomplexed ligand (L) times corresponding proportinality constants $\left(k_{\mathrm{L}_{p}}\right.$ and $k_{\mathrm{ML}_{p}}$ ). Here, $\left[\mathrm{L}_{p}\right]$ and $\left[\mathrm{ML}_{p}\right]$ are solved as a function of known inorganic complexation constants as well as one to three unknown (fitted parameter) organic complexation constants and capacities for reactions with one to one complex stoichiometry. The number of organic complexation reactions was determined as the number of measured responses that actually showed changes (see below). The inorganic "side reactions" were determined using National Institute of Standards and Technology (NIST) critically reviewed stability constants and an in-house chemical equilibrium solver written in MATLAB. The total concentration of each complexing inorganic consituent was determined from average seawater composition. Full details of the parameter fitting method, and MATLAB code for the speciation model, are given in Tait et al. (2015).

Free ion concentrations were estimated at the published $\mathrm{EC}_{50}$ values for these samples using the best-fit $\log K$ and $L_{T}$ values for each of the types of fluorphores demonstrating fluorescence quenching in each sample. The calculation involved running the same NISTbased inorganic speciation model (Tait et al., 2016) used in the RW fitting but now including the best-fit RW parameter results. To estimate the uncertainty a Monte Carlo analysis was performed using 0.05 absolute error on the $\log K$ values and $\pm 10 \%$ error on the ligand concentrations. These error estimates are based on the range of published values in a recent RW fitting exercise for Cerium (El-Akl et al., 2015). Statistical comparisons were performed by investigating if the $95 \%$ confidence intervals overlap or not.

\section{Results and Discussion}

Equation 1 was used to resolve the relative concentrations of each component $(H, F, W$ and $Y$ ) for each emission scan recorded during each titration. Example of the four component resolution data is shown in Figure 1. Each component (i.e. humic, fulvic, tryptophan and tyrosine) is simply the PARAFAC-resolved spectra multiplied by a proportinality factor (scalar) to describe the measured emission spectrum in a least-squares sense. An example of the measured spectra showing the contributions of each fluorophore to total fluorescence can be seen for BT before any addition of copper in Figure 1. The solid black line represents the modeled fluorescence curve which compares well to the measured fluorescence (open circles). In this example, the humic-like fraction (peak at $460 \mathrm{~nm}$ ) contributes the most to total fluorescence, followed by the fulvic-like fraction (peak at $405 \mathrm{~nm}$ ). Tryptophan- and tyrosine-like fractions (peaks at 350 and $300 \mathrm{~nm}$, respectively) show very little contribution to total fluorescence.

Once all 4 components are resolved using Equation 1 from each emission scan, measured at each addition of copper, the fluorescence quenching curves can be determined. An example of the resolved quenching curves for two fluorophores are shown for two samples, $\mathrm{NH}$ and JB, in Figure 2. In this example, Figure2a and c represent the humic-like component and $2 \mathrm{~b}$ and $\mathrm{d}$ represents the fulvic-like component. All samples had humic spectra that changed on copper addition. Most samples, except RB and CB, also had significant changes to the fulvic acid fluorescence intensity. Only a few samples (MK and $\mathrm{CB}$ ) had changes in tryptophan-like fluorescence. No samples showed changes in the tyrosine components. Only data that demonstrated fluorescence quenching were used for speciation parameter ( $\log K$ and $L_{T}$ ) fitting. Full spectra and fluorescence changes are shown in Tait (2013). 


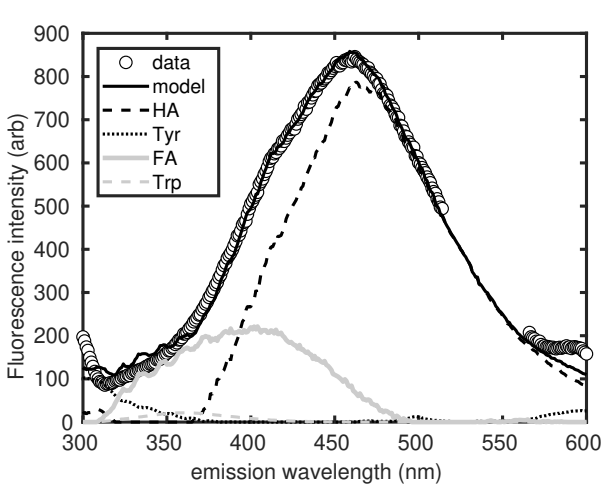

Fig. 1 Contribution of humic-, fulvic-, tryptophan-, and tyrosine-like fractions (denoted as HA, FA, Trp, Tyr respectively in the figure legend) to total fluorescence of Bouchtouche (BT)
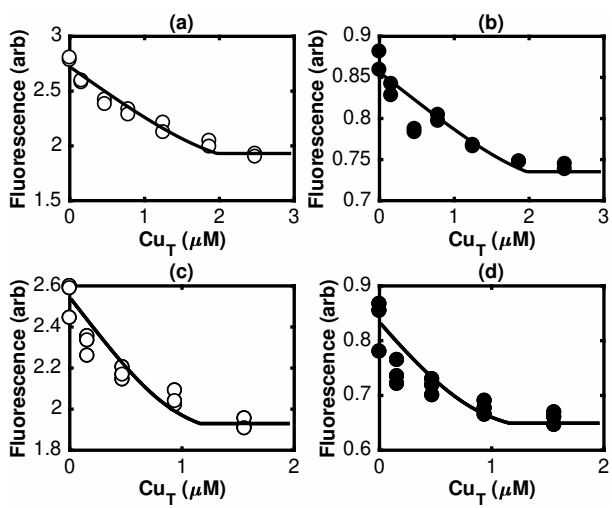

Fig. 2 Ryan-Weber fitting of the resolved fluorophores for Naufrage Harbour (NH) and Jimbo (JB). Humic components are presented as open circles (subplot (a) for $\mathrm{NH}$ and (c) for JB). Fulvic components are presented as filled circles (subplot (b) and (d) correspond to samples NH and JB respectively)

Using the fluorescence quenching data and applying a multiresponse Ryan-Weber model, the $\log K$ and binding capacities were determined for each site and are tabulated in Table 1. The binding capacities are expressed as per milligram of carbon as it is assumed that the abundance of these sites would change with DOC concentration. For all fluorophores, the binding is relatively strong for all sites ranging from 7.64 to 10.2. Chadwick et al. (2008) also showed strong binding for organic matter in San Diego Bay, with $\log$ K values for three different ligands ranged from 9.14 to 12.9. As well the binding capacities shown here covers a broad range from 15 to 3110 nmole $\mathrm{mg} \mathrm{C}^{-1}$ which encompasses the range seen in Chadwick et al. (2008) from 33.5 to 878 nmole $\mathrm{mg} \mathrm{C}^{-1}$. The values determined here are also similar to binding parameter values found in other literature for marine NOM in which $\log K$ values range from 10.0 to 14.3 and binding capacities have been found from approximately 2.5 to $>150$ nmole $\mathrm{mg} \mathrm{C}^{-1}$ (Kogut and Voelker, 2001).

The Jimbo site (JB) was previously measured using fluorescence quenching techniques in Tait et al. (2015). In this case, the humic-like fraction had a $\log K$ of 9.20 and a binding capacity of 890 nmole $\mathrm{mg} \mathrm{C}^{-1}$. The fulvic-like fraction displayed stronger binding with a $\log K$ of 10.38 and a binding capacity of 78 nmole $\mathrm{mg} \mathrm{C}^{-1}$. The results of this study show weaker binding for both fluorophore fractions with a $\log K$ of 8.96 and 9.02 for humic- and 
Table 1 Copper binding characterstics, stability constant $(\log K)$ and binding capacity $\left(L_{T}\right)$, of nine seawater samples. ${ }^{a} L_{T}$ in $\mathrm{nmol} / \mathrm{mg}$ of $\mathrm{C}$

\begin{tabular}{|c|c|c|c|c|c|c|c|c|c|}
\hline \multirow[t]{2}{*}{ Site } & \multirow[t]{2}{*}{ ID } & \multirow{2}{*}{$\begin{array}{l}\text { DOC } \\
\mathrm{mg} \mathrm{C/L}\end{array}$} & \multirow{2}{*}{$\begin{array}{l}\text { Salinity } \\
\text { (ppt) }\end{array}$} & \multicolumn{2}{|c|}{ Humic-like } & \multicolumn{2}{|c|}{ Fulvic-like } & \multicolumn{2}{|c|}{ Tryptophan-like } \\
\hline & & & & $\log K$ & $L_{T}^{a}$ & $\log K$ & $L_{T}^{a}$ & $\log K$ & $L_{T}^{a}$ \\
\hline Bouctouche & BT & 4.83 & 30.1 & 8.58 & 1250 & 8.72 & 508 & - & - \\
\hline Petit Rocher & PR & 2.10 & 30.2 & 8.87 & 476 & 8.85 & 487 & - & - \\
\hline Major Kollock Creek & MK & 7.57 & 29.9 & 9.74 & 15 & 9.59 & 154 & 9.74 & 151 \\
\hline Naufrage Harbour & $\mathrm{NH}$ & 5.20 & 29.9 & 8.42 & 1530 & 8.16 & 1800 & - & - \\
\hline Rathtrevor Beach & $\mathrm{RB}$ & 1.37 & 30.1 & 10.2 & 232 & - & - & - & - \\
\hline Hawke's Bay & $\mathrm{HB}$ & 1.28 & 30.0 & 8.25 & 3110 & 7.64 & 392 & - & - \\
\hline Blackberry Bay & $\mathrm{BB}$ & 2.03 & 29.9 & 9.40 & 481 & 9.30 & 419 & - & - \\
\hline Chesterman Beach & $\mathrm{CB}$ & 0.55 & 30.1 & 9.4 & 911 & - & - & 9.4 & 575 \\
\hline Jimbo's Bar & JB & 1.13 & 30.1 & 8.96 & 433 & 9.02 & 48.6 & - & - \\
\hline
\end{tabular}

fulvic-like fractions respectively. For humic-like fractions the binding capacity was about half (433 nmole $\mathrm{mg} \mathrm{C}^{-1}$ ), similarly the fulvic fraction was reduced by a factor of 2 at 48.6 nmole $\mathrm{mg} \mathrm{C}^{-1}$. The differences in binding parameters may have been due to differences in the sampling site between times of collection. The sample collection of Jimbo for Tait et al. (2015) occurred in January 2011, while collection for this study occurred two years later in January 2013. During the time between sampling dates, remediation efforts in the area had begun and so changes in NOM characteristics were not necessarily unexpected.

Previous research with copper and marine organisms has shown that measured free ion using ion selective electrodes is close to constant when measured at the $\mathrm{EC}_{50}$ concentration of total dissolved copper (Cooper et al., 2014; Tait et al., 2016). This observation is consistent with BLM predictions that for a constant toxic response the free ion concentration should be constant. Cupric ion selective electrodes are not easy to use though; they have long equilibration times and ideally a one-point internal calibration method should be used to correct for matrix effects and fouling (Tait et al., 2015). The fluorescence quenching method used here is much simpler to implement. The reaction times are fast (15 minutes) and the measurement of fluorescence spectra is a relatively routine laboratory tool. To represent useful speciation data though, relevant in the toxicological window of sensitive marine organisms, the free ion determined using the speciation parameters determined by fluorescence quenching must still show constant response at the total dissolved copper $\mathrm{EC}_{50}$ values. This is indeed the case as shown in Figure 3. Not only is the estimated free ion very similar for all samples (approximately $\pm 0.2 \mathrm{nM}$ ) the confidence interval for each free ion estimate overlaps with the range of $\left[\mathrm{Cu}^{2+}\right]$ calculated from the total dissolved $\mathrm{Cu}$ in the artificial seawater controls (dashed lines in Figure 3).

The constant free copper measured using fluorescence quenching is consistent with the ion selective electrode-measured free copper and toxicity results found by Tait et al. (2016). This suggests that differences in water chemistry, such as binding capacities of the waters, alter the total dissolved copper required to reach a critical free copper concentration that results in toxicity; thus, a BLM approach could take these effects quantitatively into account, and be useful in setting site-specific discharge criteria for copper in salt water environments.

Fluorescence quenching techniques have been widely used to characterize NOM interactions with copper in a variety of media (da Silva et al., 1998; Smith and Kramer, 2000; $\mathrm{Wu}$ and Tanoue, 2001; Chen et al., 2013)). However, there has been limited use of these techniques in sea water. Previous validation of fluorescence quenching techniques to characterize NOM and copper binding in artificial seawater was performed by Tait et al. (2015) 


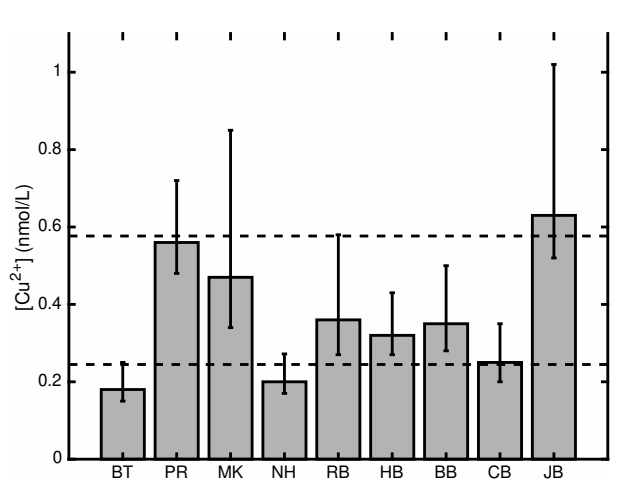

Fig. 3 Free ion estimates (bar) using fluorescence quenching results for total copper input as the measured $\mathrm{EC}_{50}$ concentration. The error bars correspond to $95 \%$ confidence estimates determined using monte carlo analysis. The dashed lines correspond to the calculated free ionic copper at the upper and lower $95 \%$ confidence limits for the $\mathrm{EC}_{50}$ in artificial seawater

and suggested good applicability in marine waters, because cupric ion estimated by fluorescence and ion-selective electrode agreed in the range of total copper known to cause toxic responses to sensitive organisms. The findings of this study further validate the use of fluorescence quenching, as a simpler alternative to ion-selective electrodes, in marine water. Measured binding parameters are consistent with literature data for marine NOM. Free copper values determined via the fluorescence data showed constant free copper concentrations at the various $\mathrm{EC}_{50}$ values and the free ion estimates agree with free ion estimates for rotifer toxicity in the absence of organic matter. These findings agree with, and support the results from Tait et al. (2016), where ISE was the analytical method. The data presented here support the theory that a critical free copper concentration is required to cause toxicity, however differences in water chemistry, such as copper binding capacity to organic ligands, alter the total amount of copper needed to be added to a system to reach this critical concentration. Overall, the results demonstrate the strong influence of binding characteristics on copper speciation, bioavailability and toxicity to aquatic organisms upon copper exposure and confirm the applicability of fluorescence quenching techniques in marine waters.

Acknowledgements This work was supported by an NSERC CRD grant (Scott Smith, P.I) with co-funding from the International Zinc Association (IZA), the International Lead Zinc Research Organization (ILZRO), the Nickel Producers Environmental Research Association (NiPERA), the International Copper Association (ICA), the Copper Development Association (CDA), Teck Resources, and Vale.

\section{References}

Arnold WR (2005) Effects of Dissolved Organic Carbon on Copper Toxicity: implications for Saltwater Copper Criteria. Integrated Environ Assess Manag 1:34-39

Birdwell JE, Engel AS (2009) Variability in terrestrial and microbial contributions to dissolved organic matter fluorescence in Edwards Aquifer, central Texas. Journal of Cave and Karst Studies 71(2):144-156

Chadwick DB, Rivera-Duarte I, Rosen G, Wang PF, Santore RC, Ryan AC, Paquin PR, Hafner SD, Choi W (2008) Demonstration of an Integrated Compliance Model for Predicting Copper Fate and Effects in DoD Harbors. Technical Report 1973, SPAWAR, 
SPAWAR, environmental Security Technology Certification Program (ESTCP) Project ER-0523

Chen W, Guguen C, Smith DS (2013) Influence of water chemistry and dissolved organic matter molecular size on copper and mercury binding determined by multiresponse fluorescence quenching. Chemosphere 92:351-359, DOI 10.1016/j.chemosphere.2012.12.075

Cooper C, Tait T, Gray H, Cimprich G, Santore R, McGeer JC, Wood C, Smith DS (2014) Influence of salinity and dissolved organic carbon on acute $\mathrm{Cu}$ toxicity to the rotifer $\mathrm{Bra}$ chionus plicatilis. Environ Sci Technol 48:1213-1221, DOI 10.1021/es402186w

da Silva JCGE, Machado AASC, Oliveira CJS, Pinto MSSDS (1998) Fluorescence quenching of anthropogenic fulvic acids by $\mathrm{Cu}(\mathrm{II}), \mathrm{Fe}(\mathrm{III})$ and UO22+. Talanta 45:1155-1165

Di Toro D, Allen H, Bergman H, Meyer J, Paquin P, Santore R (2001) Biotic ligand model of the acute toxicity of metals I : Technical basis. Environ Toxicol Chem 20:2383-2396

El-Akl P, Smith DS, Wilkinson KJ (2015) Linking the chemical speciation of Ce to its bioavailability in water for a freshwater alga. Environ Toxicol Chem 34:1711-1719, DOI 10.1002/etc.2991

Eriksen RS, Mackey DJ, van Dam R, Nowak B (2001a) Copper speciation and toxicity in Macquarie Harbour, Tasmania: an investigation using a copper ion selective electrode. Mar Chem 74:99-113

Eriksen RS, Nowak B, van Dam RA (2001b) Copper speciation and toxicity in a contaminated estuary. Tech. rep., Department of Sustainability, Environment, Water, Population and Communities, Canberra, Australia

Kogut MB, Voelker BM (2001) Strong copper-binding behavior of terrestrial humic substances in seawater. Environ Sci Technol 35:1149-1156

McKnight DM, Boyer EW, Westerhoff PK, Doran PT, Kulbe T, Anderson DT (2001) Spectrofluorometric characterization of dissolved organic matter for indication of precursor organic material and aromaticity. Limnol Oceanog 46(1):38-48

Paquin PR, Gorsuch JW, Apte S, Batley GE, Bowles KC, Campbell PG, Delos CG, Toro DMD, Dwyer RL, Galvez F, Gensemer RW, Goss GG, Hogstrand C, Janssen CR, McGeer JC, Naddy RB, Playle RC, Santore RC, Schneider U, Stubblefield WA, Wood CM, Wu KB (2002) The biotic ligand model: a historical overview. Comp Biochem Physiol Part C 133:3-35

Playle R, Dixon D, Burnison K (1993) Copper and cadmium binding to fish gills: Estimates of metal-gill stability constants and modeling of metal accumulation. Can J Fish Aquat Sci 50:2678-2687

Ryan DK, Weber JH (1982) Fluorescence quenching titration for determination of complexing capacities and stability constants of fulvic acid. Anal Chem 54:986-990

Santore R, DiToro D, Paquin P, Allen H, Meyer J (2001) Biotic ligand model of the acute toxicity of metals II: Application to acute copper toxicity in freshwater fish and Daphnia. Environ Toxicol Chem 20:2397-2402

Smith DS, Kramer JR (2000) Multi-site metal binding to fulvic acid determined using multiresponse fluorescence. Anal Chim Acta 416:211-220

Smith DS, Bell RA, Kramer JR (2002) Metal speciation in natural waters with emphasis on reduced sulfur groups as strong metal binding sites. Comp Biochem Physiol Part C 133:65-74

Sunda WG, Hanson P (1979) Chemical modeling in aqueous systems, American Chemical Society, Washington D.C., chap Chemical speciation of copper in river water, pp 147180. ACS Symposium Series 
Tait TN (2013) Determination of copper speciation, bioavailability and toxicity in saltwater environments. mathesis, Wilfrid Laurier University, URL http://scholars.wlu.ca/etd/1615 [last accessed S. Smith Dec. 15, 2017]

Tait TN, Rabson LM, Diamond RL, Cooper CA, McGeer JC, Smith DS (2015) Determination of cupric ion concentrations in marine waters: an improved procedure and comparison with other speciation methods. Env Chem 13:140-148, DOI 10.1071/EN14190

Tait TN, Cooper CA, McGeer JC, Wood CM, Smith DS (2016) Influence of dissolved organic matter (dom) source on copper speciation and toxicity to Brachionus plicatilis. Env Chem 13:496-506, DOI 10.1071/EN15123

US EPA (2007) Aquatic life ambient freshwater quality criteria - Copper. Tech. Rep. EPA822-R-07-001, Office of Water, Washington, D.C.

Wu F, Tanoue E (2001) Isolation and partial characterization of dissolved coppercomplexing ligands in streamwaters. Environ Sci Technol 35:3646-3652 